\title{
Vaivéns literários hoje: Brasil/Portugal ${ }^{1}$
}

\section{Isabel Pires de Lima}

Universidade do Porto - ILCML

Resumo: Nos inícios do século XXI, Portugal e o Brasil viram transformar-se a tipologia das suas relações interculturais e o sentido dos trânsitos das ondas migratórias entre os dois países. De cais de partida, que tradicionalmente Portugal foi relativamente ao Brasil, passou a cais de chegada para, hoje, de novo, e na sequência da atual crise financeira, económica e social europeia, voltar a ser cais de partida. Procuraremos dilucidar os novos termos desses trânsitos interculturais a partir da análise de algumas obras literárias do novo século. Centraremos a atenção em obras de Alexandra Lucas Coelho, Hugo Gonçalves, Luiz Ruffato, Matilde Campilho.

Palavras-chave: migrações, Alexandra Lucas Coelho, Hugo Gonçalves, Luiz Ruffato, Matilde Campilho

Résumé: Au début du XXIème siècle, la typologie des rapports interculturels entre le Portugal et le Brésil s'est transformée, ainsi que le sens de la circulation des vagues de migrations entre les deux pays. Étant traditionnellement un quai de départ vers le Brésil, le Portugal s'est transformé en quai d'arrivée et aujourd'hui il est devenu à nouveau un quai de depart. En partant de l'analyse de quelques œuvres littéraires du XXIème siècle, on étudiera les nouvelles nuances de ce va-et-vient. On fera attention aux œuvres d'Alexandra Lucas Coelho, Hugo Gonçalves, Luiz Ruffato, Matilde Campilho.

Mots-clé: migration, Alexandra Lucas Coelho, Hugo Gonçalves, Luiz Ruffato, Matilde Campilho 
Brasil onde vivi, Brasil onde penei, Brasil dos meus assombros de menino: Há q anto tempo já que te deixei, Cais do lado de lá do meu destino! Que milhas de angústia no mar da saudade! Que salgado pranto no convés da ausência! Chegar. Perder-te mais. Outra orfandade, Agora sem o amparo da inocência.

Dois pólos de atração no pensamento! Duas ânsias opostas nos sentidos! Um purgatório em que o sofrimento Nunca avista um dos céus apetecidos. Ah, desterro do rosto em cada face, Tristeza dum regaço repartido! Antes o desespero naufragasse Entre o chão encontrado e o chão perdido.

A sociedade pós-industrial, posterior à Segunda Guerra Mundial, viu-se, como é sabido, sujeita a processos muito intensos de aceleração que a revolução informática da comunicação global agudizou de modo exponencial. 0 mundo contemporâneo é feito de permanentes instabilidades, onde quase todas as âncoras se tornaram ineficazes. 0 próprio conceito de território, chão seguro onde lançar âncoras, se viu substancialmente alterado e o homem confronta-se com novos nomadismos, constantes experiências de deslocação, rápidos trânsitos através já não dos mares mas dos espaços siderais que o confrontam de modo muito mais frequente e acelerado com o outro, outrora longínquo e pouco mais que imaginado.

A par disto, o homem europeu da pós-modernidade, ao ter perdido o seu lugar de 
centro, perdeu segurança epistemológica e ontológica. Agudas crises de identidade, já esquecidas após a erupção dos nacionalismos do século XIX, manifestaram-se um pouco por toda a Europa. Fenómenos políticos marcantes da segunda metade do século XX, dos quais importa destacar o fim do colonialismo formal com a referida perda de centralidade europeia, o esboroamento do império soviético, a queda do muro de Berlim e a subsequente instabilidade de fronteiras a Leste e sobretudo no Cáucaso, assim como o alargamento do que veio a chamar-se União Europeia e a sua presente crise interna contribuíram também para uma certa insegurança identitária e para a precipitação das experiências de deslocação. Tudo isto para além ou intimamente ligado ao estabelecimento do capitalismo global, à emergência de novas potências económicas, em especial a China e o Brasil, e àquilo que, à falta de designação mais precisa, se tem chamado, na Europa, de crise - crise financeira, depois crise económica, agora crise social e crise de governança política europeia.

Portugal, "jardim da Europa à beira mar plantado", na fórmula célebre de um poeta português de oitocentos, viveu, nos últimos 40 anos, no quadro global acima referido, mudanças profundíssimas que suscitaram alterações ora conturbadas ora paulatinas na sua cartografia social e identitária. Após quarenta anos de regime ditatorial fascizante e de mais de dez de guerra colonial, Portugal reaprende, a partir de 1974, a democracia política, inicia-se na cidadania participativa e reencontra-se, após uma saga imperial de cinco séculos que o levou a uma primeira experiência de globalização, com as suas fronteiras medievais e com a sua dimensão europeia de pequeno rectângulo de terra bordejando o Atlântico. De centro de um império multi-continental, de cais de partida para o mundo, Portugal reassume-se como periferia, política e geograficamente relativamente à Europa, à qual retorna finda a sua era navegante, integrando-se no projecto económico e depois político da União Europeia, passando doravante a reconhecer-se também como cais de chegada.

De país tradicionalmente ligado à diáspora e, nos séculos XIX e XX, à emigração para o novo e o velho mundo, sendo ainda hoje o país da UE com mais percentagem de população emigrada (mais de1/5 da população residente), Portugal passa também a percepcionar-se 
como país de acolhimento e de imigração, a qual hoje constitui (cerca de $5 \%$ da população residente). Logo nos anos 70, meio milhão de colonos regressam subitamente à antiga metrópole. Depois, ainda no século XX, vagas de imigração proveniente das ex-colónias africanas começam a fazer-se sentir, muito especialmente vindas de Cabo Verde, Angola e Moçambique. Na viragem para o século XX, o Brasil, destino de milhões de portugueses durante séculos a fio, começa a fornecer uma imigração numerosa. Pela mesma altura, imigrantes provenientes do leste europeu - russos, ucranianos e moldavos, sobretudo - e também da longínqua China desaguam em Portugal em volumosas ondas imigratórias.

A partir de 2007, com o eclodir da crise, designadamente com o crescimento negativo, eufemismo contemporâneo para dizer retracção económica, e com o aumento avassalador do desemprego que galgou cerca de dez pontos percentuais para atingir números que chegam a rondar os 16\%, vamos assistir a uma alteração deste último quadro. Destes novos imigrantes, uma forte percentagem, que havia chegado a Portugal, nas décadas de 80 e 90, atraídos pela vasta oferta de emprego no sector da construção civil que havia crescido a forte ritmo com as obras infra-estruturais levadas a cabo com fundos chegados da União Europeia e com o alargamento do mercado imobiliário ao qual muitos portugueses acediam pela primeira vez em busca de uma habitação digna, é forçada a abandonar Portugal. Imigrantes brasileiros também começam a deixar o país, aliciados complementarmente pelo forte crescimento económico e pela implementação de políticas sociais renovadas no Brasil, assim como pela emergência de uma nova classe média à qual aspiram.

A par deste movimento, assiste-se, em idêntico período, a um aumento da emigração portuguesa, com cerca de meio milhão de portugueses a deixarem o país para destinos tradicionais daquela, nos quais o Brasil se inclui, mas sobretudo para a UE onde são cidadãos de pleno direito. Dessa nova emigração faz parte, ao contrário do que era tradição na emigração portuguesa, uma população altamente qualificada, nascida do crescimento exponencial que Portugal alcançou nos campos da educação e ciência, resultado das políticas posteriores ao 25 de Abril e sobretudo das fomentadas nas décadas de 90 e 
primeira deste século, o que provocou um aumento em cerca de $50 \%$ dos diplomados no seio dos emigrados portugueses.

0 quadro que acabei de enunciar gerou inevitavelmente perplexidades e questionamentos identitárias conduzindo à eclosão, logo na década de 80, de uma multiplicação de ensaios e ficções em torno do devir colectivo e da interrogação sobre a existência de uma identidade portuguesa, como se os portugueses duvidassem de que existem como nação firmada em fronteiras territoriais seculares, fixadas praticamente nos termos actuais pelos finais do século XIII, isto é, cerca de um século após o nascimento do estado português, em 1143.

A literatura portuguesa contemporânea tem sido permeável a estas novas realidades e da pena de escritores de diferentes gerações têm vindo a lume criações onde pensar a realidade portuguesa e a configuração das subjectividades implica a presença angular dos fenómenos da imigração e da emigração. Estes potenciam alterações profundas, perturbadoras e enriquecedoras quer nas relações humanas em contacto com o outro transportador da diferença capaz de conduzir à abertura a novos mundos interpessoais, quer na auto-percepção e auto-compreensão do próprio país enquanto colectividade em processo de refundação identitária.

Dado que de "percursos interculturais luso-brasileiros" hoje aqui se trata, vou centrar a minha atenção em 4 obras muito recentes - uma brasileira e três portuguesas nas quais trânsitos de identidade, vivências interculturais, identidades híbridas, experiências de alternância «entre dois» mundos, quotidianos de guetização, evidenciam o lugar angular das experiências migratórias como força criativa e holística. Esta desproporção de três títulos portugueses e um brasileiro, de certo modo explica-se pelo facto da emigração mais qualificada, como é a recente emigração portuguesa para o Brasil, assumir mais facilmente e rapidamente a palavra do que uma emigração tradicional com um nível de qualificação menor.

Aliás, o autor da novela brasileira de que falarei, Luiz Ruffato, que publicou, em 2009 no Brasil, Estive em Lisboa e Lembrei de Você, que aparecerá em 2010 em Portugal, com o título, Estive em Lisboa e lembrei-me de ti, nem sequer é um emigrante, como sabem. 
Procurarei compensar a desproporção detendo-me mais nesta obra que nas restantes. As obras portuguesa que convocarei serão o romance de Hugo Gonçalves, Enquanto Lisboa Arde, O Rio de Janeiro Pega Fogo, de 2013, o livro de crónicas de Alexandra Lucas Coelho, Vai, Brasil, de 2014, e o livro de poemas de Matilde Campilho, Jóquei, igualmente de 2014.

O livro de Luiz Ruffato é de certo modo uma narrativa de aprendizagem, como acontece frequentemente com as histórias de migrações, que todavia quer chamar si o tom de documento-denúncia de uma história típica de imigração. 0 próprio título revela essa intenção documental remetendo mais para o autor e o seu projecto de escrita do que propriamente para o conteúdo da história contada. Os dois para-textos prévios à novela confirmam tal pretensão documental: o poema de Miguel Torga, "Brasil” que citei em epígrafe (Torga: 418), autor português que conheceu ele próprio a experiência da dureza da emigração no Brasil, a que o dito poema alude, e uma Nota explicativa do depoimento verídico que estaria na origem do romance, esbatendo-se, assim, fronteiras entre realidade e ficção. Serginho, protagonista e narrador, com pouco discernimento crítico relativamente ao que narra, conta a sua história de vida, cujas rédeas não domina em Lisboa, como não dominava em Cataguases, aldeia do interior do Brasil, donde provém.

Serginho, já passado dos 30 anos, é um pobre diabo, com alguma coisa de pícaro ingénuo, ludibriado por todos em Portugal, como fora no Brasil, pela família, pelos amigos, por conhecidos e desconhecidos e que pouco ou nada vai aprendendo com a vida. Ao longo da novela não se assiste à auto-configuração de uma subjectividade, ao forjar de uma identidade; pelo contrário, o romance termina com Serginho, seis anos volvidos, clandestino, indocumentado, remetido para a tarefa menor de ajudante de pedreiro numa construção medíocre na periferia de Lisboa e tendo recomeçado a fumar. Ora ele chegara a Portugal na sequência da decisão promissora de vida nova, liberto do tabaco, de passaporte em punho, certo de regressar rapidamente e enriquecido, passando a ser chamado de Doutor Sérgio e a viver de rendas ${ }^{2}$. 0 romance consuma o casulo circular da despossessão de si e do mundo dentro do qual Serginho se encerra.

Pela mão de Serginho, lê-se os espaços e as convivências típicas da imigração: a pensão barata, a prostituição, a droga, a contratação e o despedimento fácil, as máfias. Pelo 
viés da incapacidade de Serginho para ler o mundo 3 , a realidade resulta denunciada como se se desse a ver sem o filtro crítico de uma subjectividade.

Raramente é a voz de Serginho que o leitor ouve fazendo tal denúncia. De um modo geral são as vozes dos outros que permitem denunciar o mundo cruel da imigração onde alguns são ao mesmo tempo vítimas e algozes, como Sheila, vítima de tráfico de carne branca e de preconceito social - "Brasileira? Então é rameira", estipula a dona do restaurante - e cúmplice da máfia organizada ligada ao tráfico de passaportes, enganando sem escrúpulo o seu incauto amigo Serginho. Será Sheila, por exemplo, que contará a sua história, verdadeira ou inventada, pouco importa, mas paradigmática de jovem sem esperança do interior do Brasil até ser apanhada numa rede de "moças recrutadas para Espanha” (Ruffato: 68). Também será o amigo Rodolfo que dará voz à despossessão identitária quando diz: "«Nós estamos lascados, Serginho», aqui em Portugal não somos nada, «Nem nome temos», somos os brasileiros"(Ruffato: 80) e à hibridez decorrente de quem vive «entre dois» espaços geográficos e afectivos:

«É ilusão, Serginho», pura ilusão imaginar que uma hora a gente volta pra nossa terra, «Volta nada», a precisão drena os recursos. «É a mãe doente na fila do SUS, é o pai com câncer de próstata que precisa de um remédio caro, é um irmão que estuda, uma irmã que casa, um sobrinho problemático», os cabelos caem, a pele enruga. (Ruffato: 81)

O depoimento de Rodolfo entra em sintonia com alguns dos versos de Torga citados em epígrafe:

Dois pólos de atracção no pensamento!

Duas ânsias opostas nos sentidos!

Um purgatório em que o sofrimento

Nunca avista um dos seus apetecidos.

Ah, desterro do rosto em cada face,

Tristeza dum regaço repartido!

Antes o desespero naufragasse

Entre o chão encontrado e o chão perdido. 
O ferrete da hibridez, enquanto impossibilidade de configuração de uma identidade plena, no lugar da fissura de que o poeta fala, é também corporizada no romance pela voz de um português com experiência emigrante, o "seu" Carrilho, que partilha a mesma pensão de Serginho. Perdida a fortuna acumulada em cinquenta anos de Brasil, "seu" Carrilho, "que gosta dos brasileiros e detesta os conterrâneos"(Ruffato: 49), tentara reencontrar os parentes deixados na aldeia de origem no Norte de Portugal, "mas já ninguém sabia dos Carrilhos, (...) nem a casa onde nasceu estava mais de pé, e, assim, «Sem passado e sem futuro» (Ruffato: 50-1) ficou.

Cabe, porém, à voz de Serginho, a captação, consciente ou não, pouco importa, daquilo que entendo ser uma bela metáfora da experiência do gueto vivida pelo imigrante. No Rossio, a antiga praça central da Lisboa antiga, lugar de concentração dos imigrantes que vivem na cidade velha e local de partida do comboio que acede a alguns dos maiores bairros de imigrantes na periferia, Serginho "ficava olhando praqueles pobre-diabos, africanos, árabes, indianos, babel de raças e cores, se espremerem dois-três na mesma cabina de telefone, esgoelando, chorando" (Ruffato: 75). Não poderá esta cabine telefónica funcionar como metáfora da experiência da guetização, da incomunicabilidade pública versus comunicabilidade guetizada que todo o imigrante conhece? Pergunto-me: O pobre diabo Serginho, afinal, não terá ele sempre vivido numa cabine telefónica, num gueto em círculo fechado como a sua história? E o facto de ter voltado a fumar não funcionará como símbolo do retorno, como num círculo, ao ponto de onde partira quando inicia a sua aventura migrante?

Vale aqui uma referência breve ao filme de 2004, Lisboetas, de Sérgio Tréfaut ${ }^{4}$, um português nascido no Brasil, o qual constitui uma viagem a uma Lisboa desconhecida para o lisboeta comum, a Lisboa das comunidades de imigrantes e dos seus problemas específicos. Tal como Luiz Ruffato, 0 cineasta pretende dar voz aos imigrantes, a esses novos lisboetasoutros que não vemos nem ouvimos mas com os quais nos cruzamos quotidianamente. É o olhar deles que norteia o filme, é a voz deles que se faz ouvir - o seu olhar e voz fazem-se denúncia. 0 filme confronta-nos reiteradamente com cenas lancinantes de incomunicabilidade e com cenas de comunicabilidade telefónica com as famílias. 0 telefone 
é uma espécie de ponte que se lança entre cais de partida e de chegada e funciona no filme como uma metáfora da espera dos que cá estão e dos que lá ficaram.

Centrarei agora a minha atenção nos três títulos portugueses acima referidos.

Enquanto Lisboa Arde, O Rio de Janeiro Pega Fogo, de Hugo Gonçalves, é dos três, pela sua própria natureza romanesca, o mais cerradamente estruturado nas mais de 300 páginas que o constituem. Também ele se apresenta como uma narrativa de aprendizagem com qualquer coisa de romance de acção e mistério e uma vertente fortemente pícara ${ }^{5}$. Não deixa, porém, de querer ser lido também como um romance de emigração, aliás dedicado "aos que deram o salto" (Gonçalves: 7), expressão portuguesa adoptada nos anos da ditadura para designar a emigração clandestina consumada por perseguidos políticos e jovens em fuga à guerra colonial.

O romance conta-nos a história do atribulado percurso carioca de um jovem adulto em fuga de Lisboa para o Rio, para evitar a perseguição de marginais com quem se vira envolvido. Lisboa, a sua cidade, pela qual se sente rejeitado, será "cais de partida" (Gonçalves:13), no início do romance, para acabar por se transformar em "cais de chegada" (Gonçalves: 312), nas últimas páginas, - e as duas expressões dão título a outros tantos capítulos - cumprindo-se também aqui o fechamento de um círculo migratório. Mas, ao contrário do Serginho, de Luiz Ruffato, a experiência migrante permitirá ao protagonista evitar ficar "doente de tuberculose melancólica" (Gonçalves: 14), que receara adquirir na pátria, e reconfigurar-se do ponto de vista identitário. A dura aprendizagem a que será sujeito no Rio de Janeiro, depois de se ter esfregado, a expressão é sua, "no lodo luxuoso de Portugal" (Gonçalves: 37), vai confrontá-lo com a experiência da perda e da frustração, condições sine qua non para poder recomeçar. No Rio de Janeiro perderá quase tudo: a casa, a bicicleta, espécie de prolongamento do corpo, garante da sua liberdade, o manuscrito de um livro que tinha o dever de escrever, a amada, o passaporte, a própria liberdade e o direito a residir no Brasil; perde até uma orelha, metáfora da metade de si que deixará para sempre ali. Mas no Rio perceberá que não pode fugir eternamente, porque como diz Tom Jobim, numa das epígrafes do livro: “A gente só leva da vida a vida que a gente leva" (Gonçalves: 9), e reaprenderá o caminho da escrita como forma de criar realidade, mundo, 
vida: "Só me restava escrever, escrever para salvar a vida. (...) Iria escrever como quem faz pão todas as manhãs. (...) Escrever todos os dias. Escrever para tapar o poço." (Gonçalves: 226-7) Aprenderá a não querer tudo e a saber o que quer: "Não peço mais do que isso: escrever." (Gonçalves: 227)

Digamos que a experiência da emigração foi apocalíptica para o protagonista: se para ele Lisboa ardia, o Rio de Janeiro pegará fogo nele, mas o apocalipse deixa-o vazio e limpo, pronto para iniciar o caminho da redenção pessoal e para se reconciliar com o seu país. Nas últimas palavras do romance, o protagonista enuncia o título do livro que está a escrever, bebido no verso camoniano: "Onde a terra acaba e o mar começa". Título e local da sua enunciação, o cabo da Roca, ponto mais ocidental da Europa, ganham uma dimensão mítico-simbólica que remete para a ideia de começo, recomeço, abertura ao mundo. Aliás, a momentos de deixar solo brasileiro, o protagonista evoca numa bela litania o já seu e já saudoso Rio de Janeiro, a partir da reiteração anafórica de duas frases "O Rio é lindo" e "O Rio é foda", que termina assim: "Rio de Janeiro: ninguém disse que eras fácil. Também não suspeitava de que fosses glorioso. Tu me destróis e tu me dás vida. Em ti recomecei. Em ti me fiz mais homem. Como poderia virar-te a cara?" (Gonçalves: 312)

O contacto com o outro levou-o a entender-se melhor também na sua identidade individual e na sua pertença a uma nação, uma identidade culturalmente híbrida. A si próprio ele diz num capítulo sugestivamente intitulado, "A arte de pedalar nas ruas do Rio de Janeiro (durante a noite)":

(...) no Rio de Janeiro, enquanto imigrante ilegal, percebeste que tinhas em ti uma portugalidade crónica, séculos de transmissão genética e séculos maculados pelo nevoeiro da esperança. Percebeste também que tudo aquilo que mais te incomodava em Portugal sempre procriou dentro de ti e deu á luz nos teus atos: o desleixo, a bonomia, o chico-espertismo, anos a confundir consumo com felicidade.

És o filho da democracia, a criança mimada da família, a geração portuguesa mais europeia de sempre, e mais educada, mais preparada, e agora mais deprimida. És um lisboeta que se enternece quando em vez de castanhas se vendem morangos e cerejas na Praça do Rossio. És judeu e árabe e magrebino e preto e celta e lusitano e ibérico e transatlântico. 0 teu avô emigrou, o teu pai também. És parte da torrente do sangue que circula pelo mundo. (Gonçalves: 255-6) 
Também os livros de Alexandra Lucas Coelho, crónicas, e de Matilde Campilho, poemas, dizem esta experiência de dupla face da fractura e da consciência identitária que a migração proporciona.

Numa crónica em que se relata um momento de preparação para a primeira experiência de um desfile no sambódromo, a cronista está dividida entre os versos do samba-enredo que tem que decorar e a audição no intervalo de cada repetição da guitarra genuinamente portuguesa de Carlos Paredes, e comenta: "Ser português tem muitas entradas e não tem saída. Ou será ao contrário? Ou será da chuva?" (Coelho: 58) A agudização de uma consciência identitária com as suas singularidades vai-se tornando mais premente à medida que o tempo vai escoando e o contacto com a realidade nova brasileira se vai intensificando. Uma crónica liricamente chamada “Não chega de saudade” diz:

Portugal nunca bastou a Portugal. - e dá-se exemplos, Vieira, Camões, Pessanha, Wenceslau de Moraes, Fernão Mendes Pinto (e continua) - Partimos porque não podemos ficar, voltamos porque nunca partimos. Há sempre uma distância entre nós e nós, e daí vem o melhor do que temos sido, as várias vidas da poesia, além da falada. É por isso que nenhum português podia ter escrito «Chega de Saudade» (Vai minha tristeza / e diz a ela que sem ela não pode ser...) Não damos ordens à tristeza ou a tristeza não nos obedece. A tristeza obedece ao Brasil e isso é o chorinho, é um samba de Paulinho da Viola, a bossanova de Tom Jobim. O Brasil cria dominando a tristeza: «Chega de Saudade». Portugal precisa que a saudade não acabe. (Coelho: 262-3)

Ora, sabemos, pelo menos desde a formulação poética de Teixeira de Pascoaes, que o futuro em português não prescinde da saudade: "Tenho às vezes saudades do futuro", disse o poeta.

Matilde Campilho também testemunha esse movimento duplo do eu migrante no processo complexo de reconfiguração da identidade, que implica movimentos de rejeição e de reclamação identitária. O poema “Tenho planos para uma confissão", não omitindo referências identificadoras do lugar de elocução (Ipanema, suco de acerola, água de coco, café da manhã, quadra) diz quanto "Eu queria distinguir-me de mim mesmo" (Campilho: 128) e quanto esse desejo de se percepcionar em duplo decorre da experiência da migração. 
Diz o poema: "Eu ia esculpindo um novo genoma / Com mãos encharcadas de água de coco//meu rosto não se transformava/mas a paisagem sim" (Campilho: 127).

No belo poema "Golpe de 7 graus", de um modo mais dramático e através da revisitação intertextual do surrealista português, Manuel de Castro, parcialmente citado em epígrafe ${ }^{6}$, Matilde Campilho fala ainda da divisão interior do ser em exílio, perdido pelos sete caminhos do mundo mas respondendo de forma reiteradamente idêntica mas sempre diferente ao "urro doloroso/ da palavra Fidelidade", manietados pela "astrolírica saudade" e acordados "para o país de azevinho/ e da excitação colectiva/ costurada a verde e a vermelho"(as cores da bandeira portuguesa).

Ao contrário da experiência enclausurante da emigração de Serginho em Portugal, a vivência testemunhada por estes três emigrantes portugueses no Brasil tende a ser libertadora e a não se fechar no não regresso ou no regresso eternamente adiado. Aliás Matilde Campilho faz o leitor reparar que os tempos são de "migrações pendulares" (Campilho: 112) e o título do livro, Jóquei, de algum modo sugere uma permanente investida e cavalgada de alguém que segue "a época das migrações / e que (...) sempre acompanhou/ s colibris e os pinguins" (Campilho: 47).

No livro de Hugo Gonçalves, que como vimos conta uma história de ir e voltar e de recomeço, o narrador faz uma longa reflexão sobre a nova emigração portuguesa no Brasil para concluir pela sua função de promotora de aprendizagem da esperança e de fortalecimento de traços de identidade nacional:

Cada vez havia mais portugueses, todos buscando a vida, gente que abdicou dos direitos adquiridos e da fé no estado-Providência, gente que se cruza nas ruas e nos botecos com outros portugueses, com os emigrantes de outras década, os Américos, os Joaquins, os Manuéis, tão antigos que chegaram ao Rio muito antes de termos nascido. Eles saíram de um Portugal miserável e drenado pela ditadura. Nós saímos de um Portugal endividado, mais ainda (esperávamos) livre. Nós tínhamos cursos superiores. Eles talvez nem a quarta classe antiga. Mas ali estávamos. (...) No início da segunda década do milénio, o Brasil voltava a ser, como tantas vezes antes, porto de chegada e rampa de lançamento para portugueses. (...) mais do que refugiados da depressão e do endividamento, percebiam a 
inevitabilidade (e o prazer) de começar de novo. Os meninos eram menos mimados a sul do equador. Buscavam, lutavam, iam contra os obstáculos da cidade. (...) incorporavam, pela primeira vez, o sentimento - mais que o conceito - de diáspora." (Gonçalves: 152-3)

O livro de Alexandra Lucas Coelho, pelo lugar de enunciação em que a autora se encontra - uma correspondente de um jornal português - concentra mais a experiência migrante na tentativa de compreensão do outro (o Brasil), do que de si mesmo ou do emigrante português no lugar do outro. Aliás, numa das últimas crónicas, a narradora surpreende-se até que durante dois anos no Rio nunca tivesse procurado ouvir o testemunho dos velhos emigrantes, tão centrada parece estar em captar a "pujança" do Brasil (veja-se o título Vai, Brasil) para além do lugar-comum europeu e português (logo numa crónica inicial, ela diz com razão que, nós portugueses, "ao Brasil chegamos sempre com excesso de bagagem" (Coelho: 17)) e em transmitir a percepção de que "O paraíso não é aqui", nome que de resto atribui a uma crónica. E importa notar que a leitura que vai fazendo do Brasil vai sendo perpassada por múltiplas referências culturais portuguesas (bem sei que está a escrever para um jornal português) do tipo: para explicar Dalton Trevisan sintetiza: “Um Luiz Pacheco. Um João César Monteiro.” (Coelho: 295) ou para falar de A Pedra, em Minas Gerais, diz que faz lembrar Penhas Douradas na Serra da Estrela portuguesa.

Mas o livro de Alexandra Lucas Coelho não deixa de testemunhar a sua vivência carioca como experiência migrante, também alargadora de mundo e de sentimentos de pertença. Veja-se este escurso pessoal no final de uma das últimas crónicas:

Desde Fernão de Magalhães que nos lançamos ao mar porque a terra não chega. Estou a falar de nós errantes, derradeiros europeus, mas repito: (...) o mundo nunca me pareceu pequeno. Da minha casa em Lisboa podia ouvir Carminho ou Camané (fadistas portugueses) cantar às três da manhã, e emigrei. Nunca nada aconteceu no meu coração ao cruzar a Rua dos Remédios com a Calçada do Cascão, mas no ano passado ouvi Amália no Alto Rio Negro. A minha Amália é esta, a meio da volta do mundo. Jamais fui tão portuguesa. (Coelho: 272)

Procurei aqui trazer alguns trânsitos interculturais entre Brasil e Portugal que a 
literatura contemporânea dos dois países patenteia. Desse trânsito participam intensamente imigrantes e emigrados nos dois sentidos, qualquer que seja o lado do cais dos seus destinos, de que falava o poeta, sujeitos uns e outros a processos de contaminação, hibridismo, estranhamento, onde também cabe a língua comum - e gostaria de ter tido tempo para abordar o seu tratamento nos textos em causa -, quando não a processos de guetização, mas também de aprendizagem ou re-aprendizagem da esperança. E em todos os casos envolvidos de formas plurais e muito diversas na redefinição de novas identidades e de renovada consciência de pertença.

\section{Bibliografia}

Campilho, Matilde (2014), Jóquei. Lisboa, Tinta da China.

Castro, Manuel de (2013), \& etc - uma editora no subterrâneo. Lisboa, Livraria Letra Livre. Coelho, Alexandra Lucas (2014), Vai, Brasil. Lisboa, Tinta da China.

Gonçalves, Hugo (2013), Enquanto Lisboa Arde, O Rio de Janeiro Pega Fogo. Alfragide, Casa das Letras.

Mendes, Ana Paula Coutinho (2009), Lentes bifocais. Representações da diáspora portuguesa do século XX. Porto, Edições Afrontamento e Instituto de Literatura Comparada Margarida Losa (FLUP).

Ruffato, Luiz (2010), Estive em Lisboa e lembrei-me de ti. Lisboa, Quetzal.

Torga, Miguel (1981), Antologia Poética. Coimbra. 
Isabel Pires de Lima é Professora Emérita da Universidade do Porto. Professora Catedrática Aposentada da Faculdade de Letras da Universidade do Porto. Investigadora do Instituto de Literatura Comparada Margarida Losa (Unidade I\&D da FCT). Professora convidada em Universidades europeias, africanas, americanas e asiáticas. Doutorada em Literatura Portuguesa com a tese As Máscaras do Desengano - para uma leitura sociológica de 'Os Maias' de Eça de Queirós (1987); especialista em Literatura Portuguesa Moderna e Contemporânea e em estudos queirosianos com dezenas de títulos publicados; trabalha ainda em Estudos Interartísticos e em Literaturas Comparadas em Língua Portuguesa. Promotora de inúmeros colóquios e congressos nacionais e internacionais. Deputada à Assembleia da República Portuguesa (1999-2005/2008-2009). Ministra da Cultura de Portugal (2005-2008). Vice-Presidente do Conselho de Administração da Fundação de Serralves para o triénio 2016-2018. Grande Oficial da Ordem do Infante D. Henrique.

\section{NOTAS}

\footnotetext{
${ }^{1}$ Este artigo foi desenvolvido no âmbito da investigação realizada no Progra ma Estratégico Integrado UID/ELT/00500/2013 - POCI-01-0145-FEDER-007339.
}

${ }^{2} 0$ seu projecto era "descontada a pensão pra Noemi e pró Pierre, economizar ao máximo pra ir embora logo, comprar umas casas em Cataguases, viver de aluguel, fazendo nada o dia inteiro, subindo e descendo a rua do Comércio, sentar na praça Rui Barbosa pra conversar fiado, jogar porrinha, ver o mulherio desfilar, o povo, ensardinhado dentro dos ônibus, respeitoso, me cumprimentar, Boa tarde, Serginho, Serginho não, seu Sérgio, Boa tarde, seu Sérgio, não, não, Doutor Sérgio, Boa tarde, Doutor Sérgio, quem sabe candidatar-se a vereador"(Ruffato: 59).

3 Por exemplo, quando conhece Sheila, uma prostituta brasileira, entende que os seus dentes alvos e sem falhas denunciam uma "moça-de-família", pese embora todos que a olham a reconhecerem como prostituta. Mesmo assim, Serginho presume: "dificilmente erro nos julgamentos"(Ruffato: 63). Claro que a escolha do autor ao grafar a palavra dificilmente em itálico tem uma intencionalidade irónica e contrapontística. 
Um outro exemplo ocorre quando o brasileiro Rodolfo tenta fazer-lhe uma iniciação à cidade mas Serginho não apreende quase nada: "ele apontava um prédio, ma paisagem, um beco, e explicava, mas eu não entendia quase nada, ele na frente, o rosto embrulhado num cachecol, as palavras saíam abafadas, se perdiam, eu, atrás, ouvia apenas, «Aqui é o», «Lá em baixo, está vendo?, é a», «O povo daqui é», «Você tem que tomar cuidado com», «Olha o».(Ruffato: 49)

${ }^{4}$ Lisboetas, um filme de Sérgio Tréfaut, Edição Atalanta Filmes, Lisboa, 2006.

${ }^{5}$ Atente-se no teor das três epígrafes que abrem o romance:

“Vede agora se eu tinha razão para dizer que é natureza ou má condição da nossa Lusitânia não poder consentir que luzamos que nascem nela." (Padre António Vieira)

"A gente só leva da vida a vida que a gente leva." (Tom Jobim)

"Why do we fall sir? So we might learn to pick ourselves up." (Alfred Pennyworth para Bruce Wayne, Aka, Batman)

6 Eis o poema de Manuel de Castro, intitulado "Contarelo": Venho dum país de neve e floresta /cujas renas nos aquecem com o bafo / e onde deixei um filho gigantesco. / Mas que fútil triste música é esta / que no ar desenha melancólicas flores de luz / e vem acompanhada dum tinido grotesco?!! //Saudade, astrolírica saudade / teu nome é Mathilde / a voz Fidelidade / e o contorno é um pequeno cão macambúzio / feito com tinta castanha da China. / Fim. (\& etc - uma editora no subterrâneo,

Lisboa, Livraria Letra Livre, 2013). 